\title{
$\mathbf{u}^{-}$병원 환경 기반에서 상황인식 인증 보안 서비스 설계 및 구현나
}

\section{Design and Implementation of A Context-Aware Authentication Security Service Based on u-Hospital Environments}

\author{
정 창 원* \\ Jeong Chang Won
}

\author{
최 재 형** \\ Choi Jae Hyeong
}

\author{
주 수 종*** \\ Joo Su Chong
}

\section{요 약}

최근 스마트폰 시장경쟁 본격화에 따른 개방형 플랫폼 증가와 앱스토어의 등장으로 인하여 범용OS를 채택하고 있는 모바일 단말 은 모바일 악성코드의 제작을 용이하게 만들고, 제작된 모바일 악성코드는 범용OS로 인해 이식성이 높기 때문에 모바일 공격의 규모 및 피해가 점차 증가하고 있다. 그러나 현재 대응할 수 있는 보안적인 요소들은 증가하고 있는 악성 코드, 바이러스 등에 비해 매우 부족하다. 따라서 본 논문은 개인정보 침해를 포함하여 서비스의 가용성을 위협할 수 있는 스마트폰 서비스에서 발생 가능한 위험요 소를 배제하여 상황인식 인증 보안 서비스에 대해 기술한다. 제안한 시스템은 사용자의 정보 확인 절차를 부여하여, 정보유출 피해를 막고, 또한 긴급 상황에 대비하여 사용자의 정보 확인 수준을 변경하는 서비스를 구현하였다.

\begin{abstract}
The warming up of the recent competition in the smart phone industry followed by rapid increase of open platforms and app stores have led the mobile terminals to adopt the general purpose operating system. The mobile device utilizing this OS is vulnerable to mobile malignant code which is highly transferable. As a result, the scale of mobile attack and harm increase. However, compared to the malicious code and virus which keep increasing, the elements for security to prevent are insufficient. Therefore, this paper describe about the Context Aware Service that eliminates the potentially risky elements on the smart phone service, which could threaten the usability of the service including invasion of personal information. The proposed system prevents from disclosure of personal information by giving the procedure of information, and realizes the service that is able to change the sequence of identifying the users' information to prepare for emergency.
\end{abstract}

프 keyword: 상황인식 인증(Context-Aware Authentication), 안드로이드 보안 플랫폼(Android security platform), $\mathrm{u}$-병원 환경(u-Hospital environments)

\section{1. 서 론}

유비쿼터스 컴퓨팅은 빠르게 성장하는 연구 영역으로 그 사용이 주로 스마트 가정과 직장 등과 같은 스마트 공 간이라는 인프라를 기반으로 상황 인식 응용에 집중되어

\footnotetext{
* 정 회 원 : 원광대학교 컴퓨터공학과 박사후 연구원 mediblue@wku.ac.kr

** 준 회 원 : 비상에듀 jjling@wku.ac.kr

*** 종신회원 : 원광대학교 컴퓨터공학부 교수, 공업기술개발연구소 연구위원(교신저자) scjoo@wku.ac.kr
}

[2011/08/30 투고 - 2011/09/08 심사(2011/11/23 2차) - 2012/01/31 심사완료]

눈 본 논문은 2011년도 한국인터넷정보학회 하계학술발표대회 우수논문의 확장버전임.

누 이 논문은 2011년도 원광대학교의 교비지원에 의해서 수행 됨, 공업기술개발
있다[1]. 이러한 환경에서 스마트 폰기반의 응용 서비스 개발에 관한 연구가 활발해지고 있다. 그러나 기존의 승 인과 접근 제어모델기반의 보안 서비스는 동적인 유비쿼 터스 컴퓨팅 환경에 적용하기 미흡하다[2]. 이로 인하여 유비쿼터스 컴퓨팅에서 보안과 사생활 침해에 대한 문제 점이 대두되고 있다[3-5]. 특히, 이러한 문제점은 모바일 디바이스인 스마트 폰에 더욱 문제의 심각성이 활용과 비례하여 증가하고 있다. 보안 위협으로부터 스마트폰 사용자를 보호하고, 서비스 환경에 대한 안전성, 무결성, 가용성, 신뢰성을 제공하기 위한 스마트폰 보안 기술이 절실히 요구된다.

따라서, 본 논문은 개인정보 침해를 포함하여 서비스 의 가용성을 위협할 수 있는 스마트폰 상의 응용 서비스 에서 발생 가능한 보안 문제점을 해결하기 위한 상황인 식 인증 보안 서비스에 대해 기술한다. 제안한 상황인식 인증 보안 서비스는 기존 사용자의 정보 확인 절차와 상 
황기반의 사용자의 정보 확인 수준을 변경하는 서비스를 구현하였다. 그리고 수행성을 검증하기 위하여 동적인 상황 변화가 민감한 $\mathrm{u}$-병원 환경에 적용하였다.

본 논문의 구성은 다음과 같다. 2 장에서는 관련 연구 에 대한 내용을 살펴보고, 3 장에서는 본 논문에서 제안하 는 상황인식 인증 보안 서비스를 동작하기 위한 서비스 플랫폼 구성에 대해 그리고 4장에서는 상황인식 인증 보 안 서비스의 설계와 제안한 서비스의 적용 예를 통해 수 행 결과를 보인다. 마지막으로 5장에서는 결론 및 향후 연구 내용으로 끝맺고자 한다.

\section{2. 관련연구}

기존 보안 스킴은 인증과 접근 제어 기술을 근거로 로 그인과 로그아웃 그리고 승인과 같은 형태로 제공되었 다. 그러나 이러한 보안 스킴은 동적인 유비쿼터스 환경 에 적용하기 어렵다. 특히, 유비쿼터스 환경에서 다루어 지는 다양한 콘텐츠와 센서, 디바이스 그리고 단말기들이 유무선망을 기반으로 서로 동적인 상호작용이 요구된다.

따라서, 다양한 상황과 통합된 정보를 바탕으로 적응 적인 상황인식 기반의 보안 서비스가 요구된다.

상황인식 보안 기술은 기존 보안 모델인 접근 제어 모 델에서 제공하지 않는 몇 가지 요구사항을 갖고 있다. 먼 저, 사용자를 중심으로 지속적으로 변화하는 상황에 따 라 동적으로 접근 제어 정책의 변화와 사용권한을 취소 할 수 있는 기능을 갖는다. 그리고 접근제어 정책을 지원 하기 위한 다양한 상황에 대한 공통적인 표현 방법이 요 구된다. 이에 대한 대표적인 연구로는 다음과 같다.

스마트 홈 환경을 기반으로 규칙기반 접근제어 기법 을 확장한 SESAME(See A Secure European System for Applications in a Multi-vendor Environment) 연구가 있다 [6]. 이는 Gia 프로젝트의 인프라를 기반으로 하며, 멀티 레벨 인증 기법을 이용하여 상황 변화에 대처할 수 있도 록 하였다[2,6].

$\mathrm{CASCOM}$ 프로젝트에서는 e-헬스 환경에서 상황인식 보안 서비스에 대해서 제안하였다. 제안한 시스템은 시 멘틱 웹 서비스와 지능형 에이전트 기술을 이용하였다. 또한 모바일 서비스 환경으로 e-헬스케어 환경을 구축하 였다. 이러한 환경을 기반으로 건강 조건과 응급 상태에 관련된 조치 사항을 해결하기 위한 시나리오와 시스템을 위한 구조를 보였다[7].

이외에 부경대학교에서 제안한 MAUT(Multi- Attribute Utility Theory)와 확장된 GRBAC (Generalized Role-Based

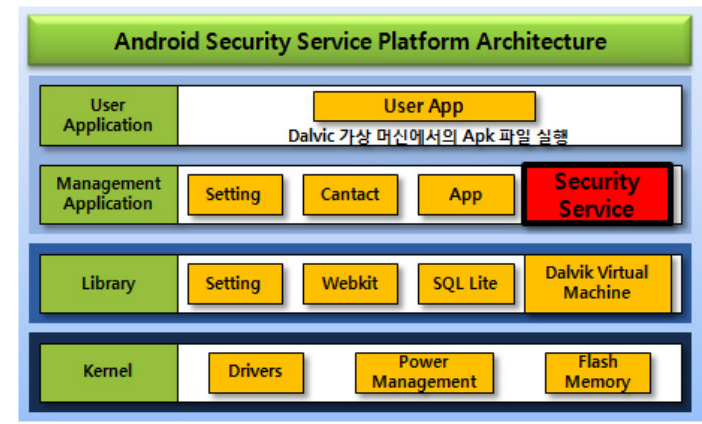

(그림 1) 안드로이드 보안 서비스 플랫폼 아키텍처

Access Control)를 이용한 상황인식 보안 서비스를 제안 하였다[8]. 제안한 보안 모델은 RFID/센서네트워크 환경 에서 EAP (Enterprise Application Framework)을 기반으로 상황인식 보안 모델의 구조를 구성하였다. 또한 적응적 보안 레벨 알고리즘을 사용자의 상황에 따르는 수행성 평가를 보였다.

앞서 언급한 바와 같이 유비쿼터스 컴퓨팅 환경에서 상황인식 보안 기술에 대한 연구는 동적인 상황에 따라 대처 할 수 있는 보안 서비스 모델과 상황정보를 수집할 수 있는 유비쿼터스 인프라를 구축한 환경 상에서 연구 가 진행되고 있다.

본 논문에서 제안하는 보안 서비스는 대표적인 연구 와 유사한 동적 접근제어 모델[9, 10]을 기반으로 한다. 그러나 본 논문에서는 모바일 디바이스인 안드로이드 OS 기반의 스마트 폰에 중점을 두고자 한다. 그리고 이 를 U-병원 환경에 적용하여 수행성을 확인하였다.

\section{3. 상황인식 인증 보안 서비스}

본 장에서는 제안한 서비스의 시스템 환경과 지원 서 비스에 따르는 보안 서비스 절차에 대해 기술한다.

\section{1 시스템 환경}

본 논문에서 제안한 상황인식 인증 보안 서비스는 4계 층으로 구성된 안드로이드 플랫폼을 기반으로 한다[11]. 우리는 기존 안드로이드 구조의 관리 어플리케이션 계층 에 (그림 1)과 같이 상황 인식 인증 보안 서비스를 제공 하는 기능을 추가하였다. 이는 디바이스로부터 사용자의 인증과 서버 측과 연계하여 3 단계 상황인식 인증을 처리 하는 역할을 제공한다. 


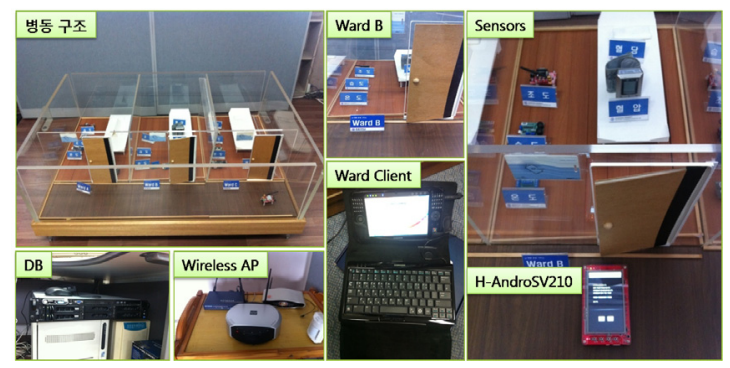

(그림 2) 상황인식 인증 보안 서비스의 물리적 환경

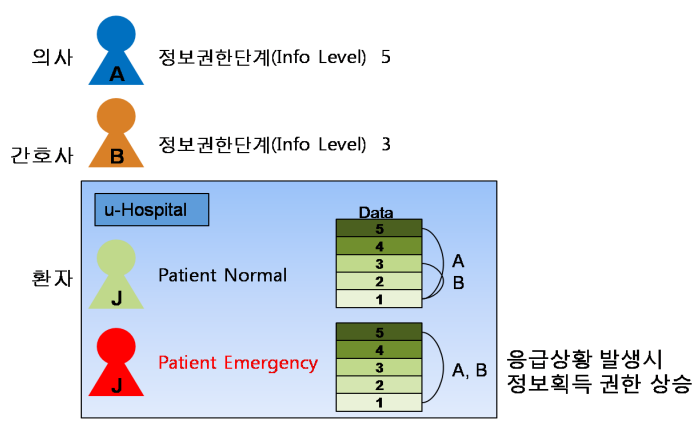

(그림 3) 정보 권한 변경에 따른 단계 조정

상황 인식 인증 보안 서비스를 위한 시스템 환경은 (그림 2)와 같다. 해당 병실마다 $\mathrm{QR}$ 코드를 인식하여 병 실 위치와 관련 정보를 로드할 수 있다. 이러한 방법으로 스마트 폰을 소지한 사용자의 위치를 판별한다. 실내 환 경 정보인 온도, 습도 정보 수집을 위한 환경 센서는 ATMega 128 마이크로 컨트롤러와 2.4GHz Zigbee 트랜시
버인 CC2420를 사용하였다. 그리고 Zigbee 기반 $\mathrm{Co} 2$ 및 조도센서 등의 환경 정보 수집을 위한 센서의 추가가 용 이하도록 센서노드와 싱크노드로 구성하였다[12].

\section{2 지원 서비스}

본 절에서는 상황 인식 인증 보안 서비스가 지원하는 서비스의 상황별 서비스 과정에 대해서 기술한다.

\subsection{1 응급 환자 발생}

병원의 각 구성원인 의사, 간호사 그리고 환자 그리고 관리자별 정보 접근 등급을 5 단계로 구분하였다.

먼저 의사의 경우 상위레벨인 5 등급으로 하였으며, 간 호사의 경우 3 등급으로 구분하였다. 이를 기반으로 정보 접근을 제한한다. 환자의 평소 상태에서는 각 역할에 맞 는 단계의 정보를 제공하지만 응급상황의 경우, 기존의 3 단계 정보권한을 갖고 있던 간호사 $\mathrm{B}$ 는 2 단계 상승하여 의사 $\mathrm{A}$ 와 동일한 정보 획득 권한을 갖게 된다. 응급상황 은 병실 내에 설치된 실내 환경 정보 센서와 환자 생체 신호 정보를 실시간 갱신하여, 정보 권한 단계 조정이 이 루어진다.

\subsection{2 정보 공유 서비스}

정보 공유 서비스는 병원의 각 병실에 따른 담당 진료 의사나 간호사의 해당정보를 권한이 없는 다른 사용자에 게 공유할 수 있는 서비스이다. 사용자의 역할에 따른 정 보 획득 방식에서 역할과 권한의 관계의 계층에 따라 보

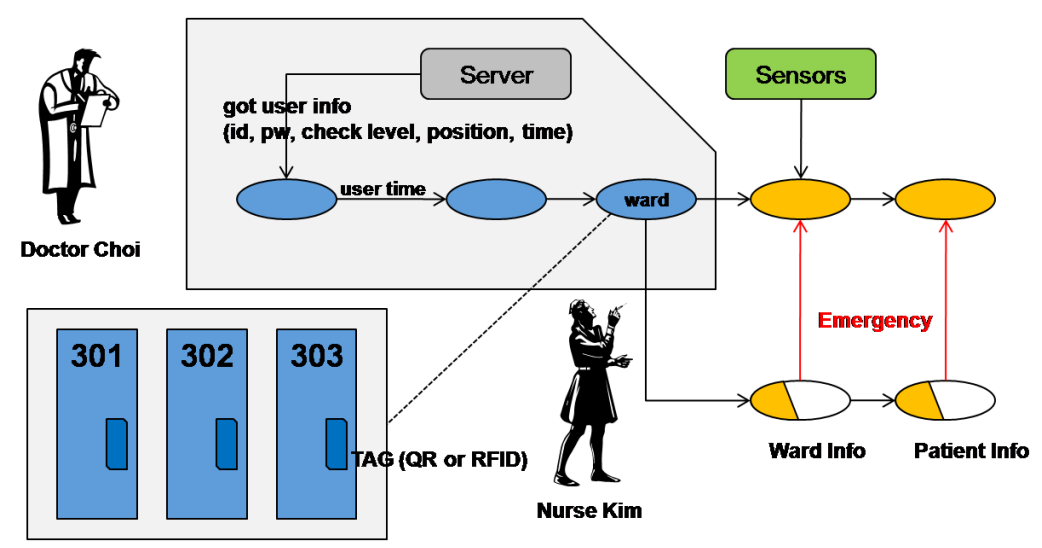

(그림 4) 응급 상황 발생 시 정보 획득 방식의 변환 


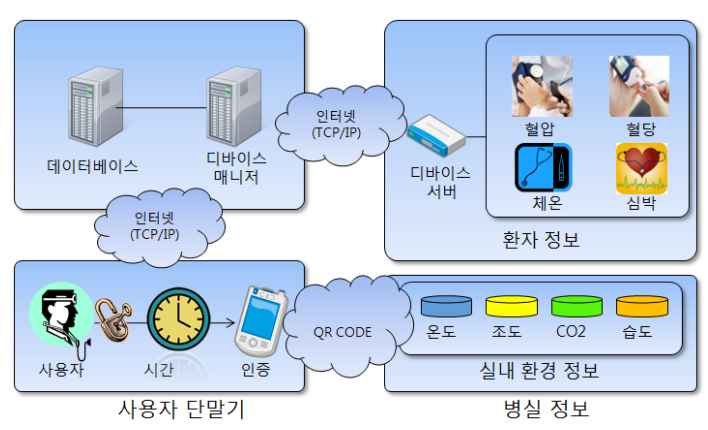

(그림 5) 상황인식 인증보안 서비스 구성도

조 의사 또는 담당 간호사가 주치의와 함께 병실에 들어 가면 동행 관계로 동일한 보안레벨로 권한을 부여하여 함께 병실 및 환자 정보를 확인할 수 있다.

\subsection{3 화재 및 각종 재난}

다양한 위험상황에 대처하기 위해 사용자에게 정보통 신망(SMS 모바일 등)을 통한 재난 상황, 위치 확인 후 경 보 메시지를 제공한다. 이로 인해, 경보 발생 상황 단계 로 넘어가 역할에 상관없이 사용자가 병원 내 제한된 정 보에 접근을 허가하여 위험상황 대처 대형피해를 최소화 할 수 있다.

\section{4. 상황인식 인증 보안 서비스의 설계 및 구현}

\section{1 구현환경}

제안한 시스템의 수행성을 검증하기 위해 실험실에 병실정보를 획득할 수 있도록 가상 병실을 모델링 하였 다. 환경 센서와 환자정보를 획득하기위한 측정기를 통 하여 디바이스 서버로 전송되는 시스템으로 구성하였다. 디바이스 서버는 센싱된 데이터를 범용으로 수집하고, 시리얼 통신을 $\mathrm{TCP} / \mathrm{IP}$ 로 변환 기능을 제공한다. 이렇게 수집된 센싱 데이터는 인터넷을 통하여 디바이스 매니저 에게 전달된다. (그림 5)는 구현된 상황인식 인증 보안 서 비스의 구성도이다.

\section{2 소프트웨어 구성 설계}

본 시스템에서 제안하는 상황 인증 서비스 수행과정 [15]은 (그림 6)과 같다. 1단계 Server Side에서 기본적인 사용자의 신상정보를 확인하며, 2.3단계는 Client Side에 서 처리되며 현재시간과 사용자의 가용시간 정보를 비교

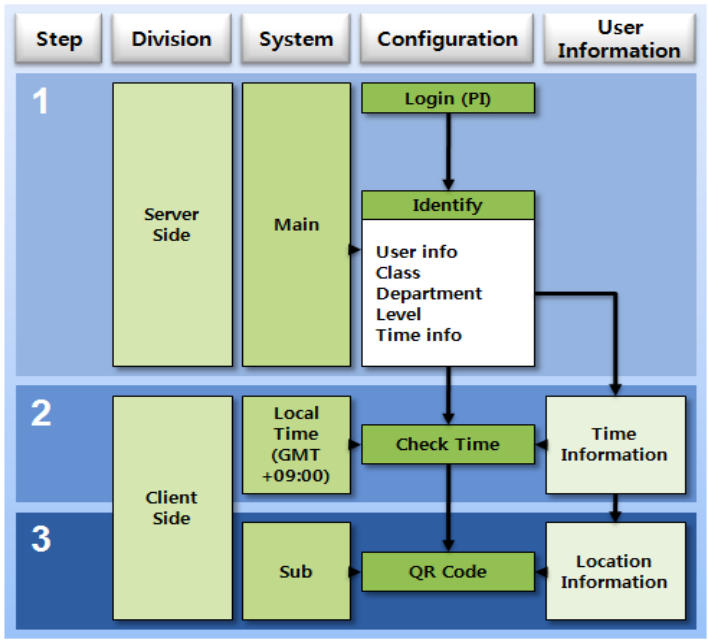

(그림 6) 상황인식 인증 보안 서비스 설계

하고, 위치 정보를 확인하는 과정을 통해 인증 절차를 수 행한다.

위치 정보는 사용자가 $\mathrm{QR}$ 코드를 인식하였을 때 해당 병실의 정보를 포함한 위치를 획득한다. 이러한 상황인 증 결과 사용자가 접근할 수 있는 서버 상의정보와 해당 위치에서 수집할 수 있는 센서로부터 데이터를 수집할 수 있다.

\section{3 응용 서비스 수행 과정}

본 절에서는 제안한 상황인식 인증 보안 서비스에서 제공하는 서비스의 수행과정을 각 결과 화면을 통해 확 인한다. 데이터 수집부분은 디바이스 서버로부터 인터넷 을 통하여 디바이스 매니저에서 수집된다.

제안한 상황인식 인증 보안 서비스의 수행성을 검증 하기 위해 응용 서비스에 적용하였다. 먼저 스마트폰에 서 사용자의 아이디와 패스워드를 통해 Server Side DB로 부터 상황인증에 필요한 정보를 받아 Client Side에서 수 집한 시간과 위치 정보로 상황인증절차를 수행한다. (그 림 11)에서는 3 단계의 상황인증 처리 수행 과정에 따르 는 결과화면을 보이고 있다.

\section{4 응용 서비스 수행 결과}

본 절에서는 제안한 보안 서비스의 올바른 수행성을 확인하기 위해 병원 정보 서비스를 위한 응용 서비스의 결과화면을 통해 보인다. 

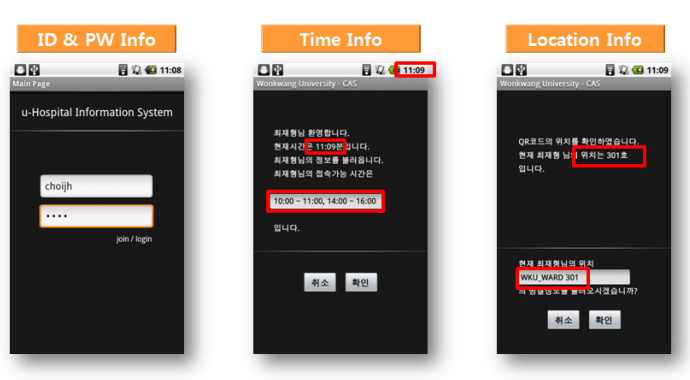

(그림 7) 각 상황 인증 처리 수행 과정

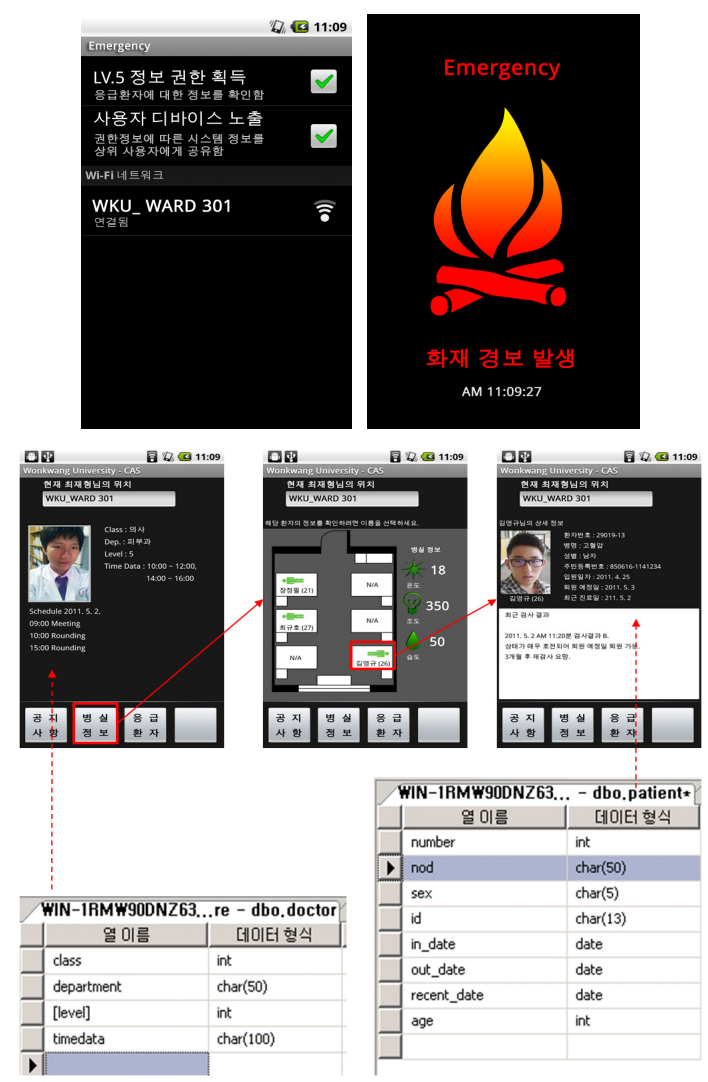

(그림 8) 서비스에서 제공하는 사용자 GUI의 수행 결과와 $\mathrm{DB}$ 테이블

(그림 7)은 사용자 인증 단계에서부터 시간과 위치에 따라 인증 처리 수행과정을 보이고 있다.

(그림 8)에서는 3단계 상황인식 인증 보안 서비스 수 행결과로 사용자 $\mathrm{GUI}$ 를 통해 담당의사가 접근 가능한 모 든 정보를 보인다. 이는 본 논문에서 제안하고 있는 상황 인식 인증 보안 서비스의 수행결과를 기반으로 한다. 서
버로부터 전송받아 담당의사의 스케줄 정보와 병실의 특 정 환자에 대한 진료 정보를 출력한 결과화면을 나타낸다. 또한 병실의 환경 센서로부터 수집된 데이터를 보인다. 담 당의사의 접속정보 화면에서 병실정보를 선택하면 $\mathrm{AP}$ 를 통해 연결되어있는 병실에 대한 모든 정보가 출력된다. 클 라이언트 $\mathrm{I} / \mathrm{O}$ 를 통해서 환경 센서 정보 및 환자 정보를 단 말기로 확인한다. 이와 관련된 데이터베이스의 일부인 담당의사와 환자 정보 테이블을 근거로 제공한다.

\section{5. 결 론}

본 논문에서는 유비쿼터스 컴퓨팅 환경에서 동적인 보안 서비스를 제공하기 위한 상황인식 보안 인증 서비 스에 대해 기술하였다. 특히, 안드로이드 기반의 플랫폼 상에 보안 서비스를 추가하였다. 그리고 인증 절차는 3 단 계로 각 사용자가 정보를 획득할 수 있는 서비스를 제안 하였다. 또한, 제안한 서비스의 수행성을 $\mathrm{u}$-병원정보 응 용 서비스에 적용하여 검증하였다. 사용자의 신상정보를 분석 파악하여 인증절차를 구성하는 상황인증 서비스는 사용자의 정보, 시간, 위치와 같은 상황정보를 토대로 인 증 받은 허가권자에 한해 정보를 획득할 수 있도록 하였 다. 그리고 응급 상황이나 화재와 같은 위험 상황 발생 시 보안레벨을 조정하여 신속하게 대처할 수 있는 서비 스를 제공하도록 하였다.

향후 제안한 상황인식 인증 보안 서비스에 다양한 상 황에 따르는 보안 메커니즘의 추가와 $\mathrm{u}$-병원 정보 서비 스를 위한 애플리케이션을 기반으로 성능평가를 수행할 예정이다. 또한 $\mathrm{u}$-병원 정보 서비스뿐만 아니라 학교, 관 공서, 기업 등의 다양한 시설에 서비스를 추가할 예정이 다. 그리고 사용자별로 보다 세분화한 상황정보를 추론 할 수 있는 사용자별 맞춤형 상황인식에 대한 연구 및 현 재 급증하고 있는 다양한 운영체제의 스마트폰 환경을 고려한 서비스 확장을 진행할 예정이다.

\section{참 고 문 헌}

[1] Wullems, C., Looi, M., Clark, A., "Towards context-aware security: an authorization architecture for intranet environments", Pervasive Computing and Communications,. pp.132-137, 14-17 March, Orlando, Florida, USA. 2004.

[2] Jalal Al-Muhtadi, Anand Ranganathan, Roy Campbel, and Dennis Mickunas, "Cerberus: A 
Context-Aware Security Scheme for Smart Space", In Proceedings of the First IEEE International Conference on Pervasive Computing and Communications, pp.489-496, IEEE Computer Society, March 2003.

[3] 정목동, “상황 인식 보안에 관한 고찰”, 情報保護 學會誌 第16卷 第2號, 2006.4, pp.37-45.

[4] 이지연, 오민경, 창병모, 안준선, 도경구 “유비쿼 터스 컴퓨팅을 위한 접근제어와 상황적응 시스 템", 한국정보과학회 2006 가을 학술발표논문집, 제33권 제2호(B), 2006.10, pp.590-603

[5] 임신영, 허재두, "상황인식 컴퓨팅 응용 기술 동 향” 전자통신동향분석 제 19 권 제 5 호 2004.10, pp.31-40.

[6] J. Al-Muhtadi, M. Anand, M. D. Mickunas, and R.H. Campbel, "Secure smart homes using jini and uiuc sesame", Uiucdcs-r-99-2142, University of Illinois at Urbana Champaign, December 1999.

[7] Antonio Lopes, Paulo Costa, Federico Bergenti, Matthias Klusch, Bastian Blankenburg, Thorsten Moller, Heiko Schuldt, "Context-aware Secure Service Composition Planning and Execution on E-Health Environments", European Conference on eHealth 2006, Proceedings of the ECEH'06,
Fribourg, Switzerland, October 12-13, 2006, pp. 179-190.

[8] Kiyeal Lee, Seokwan Yang, Sungik Jun and Mokdong Chung, "Context-Aware Security Service in RFID/USN Environments using MAUT and Extended GRBAC", Journal of Information Assurance and Security 2, 2007, pp.250-256.

[9] 김동호, 정창원, 주수종, “분산 객체그룹 프레임워 크의 보안 서비스를 지원하는 보안 정책 관리”, 한국인터넷정보학회 학술지, 제8권 2호, 2007. 10.02-03, pp.149-152

[10] Su Chong Joo, Chang Won Jeng, Seong Jin Park, "Context Based Dynamic Security Service for Healthcare Adaptive Application in Home Environments", 2009 Software Technologies for Future Dependable Distributed Systems(STFSSD. 2009.14) Tokyo, Japan 2009. 3. 17 pp 220-224

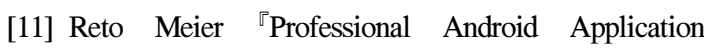
Development』Chapter 2 : Developing for Android, 2009. pp.20-29.

[12] 윤영민, 류한철, 정창원, 주수종, “상황정보 서비 스를 위한 이기종 센서정보 관리" 한국인터넷정 보학회 학술지, 제9권 1호, 2008.05.30-31, pp. 357-361. 


\section{저 자 소 개}

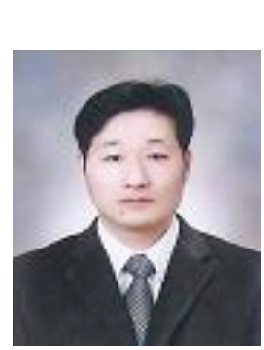

\section{정 창 원}

1993년 원광대학교 컴퓨터공학과 졸업(학사)

1998년 원광대학교 컴퓨터공학과(석사)

2003년 원광대학교 컴퓨터공학과 졸업 (박사)

2004년 2006년 전북대학교 학술연구교수

2006년 현재 원광대학교 컴퓨터공학과 박사후 연구원

관심분야 : 분산객체 컴퓨팅, 유비쿼터스 컴퓨팅, 멀티미디어 서비스, LBS.

E-mail : mediblue@wku.ac.kr

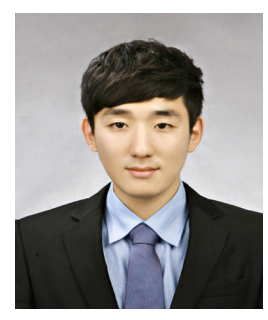

\section{최 재 형}

2010년 원광대학교 컴퓨터공학과 졸업(학사)

2010년 2012년 원광대학교 대학원 컴퓨터공학과 졸업(석사)

2012년 현재 비상에듀

관심분야 : 분산컴퓨팅, 유비쿼터스 보안, 모바일 응용

E-mail : jjling@wku.ac.kr

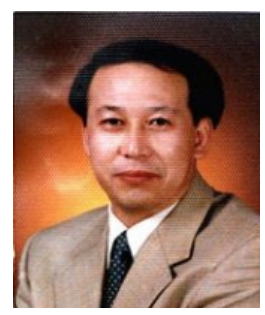

\section{주 수 종}

1986년 원광대학교 전자계산공학과 졸업(학사)

1988년 중앙대학교 컴퓨터공학과(공학석사)

1992년 중앙대학교 컴퓨터공학과 졸업 (공학박사)

1993년 미국 University of Massachusetts at Amherst, Post-Doc.

2002년 2004년 미국 UC at Irvine, Visiting Professor.

2007년 2009년 원광대학교 정보전산원 원장

2009년 2010년 UC at Irvine, Dept of EECS, Visiting Professor

1990년 현재 원광대학교 컴퓨터공학부 교수

관심분야 : 분산 실시간 컴퓨팅, 분산객체모델, 시스템 최적화, 멀티미디어 데이터베이스

E-mail : scjoo@wku.ac.kr 